http://dx.doi.org/10.5007/2175-7968.2014v1n33p143

\title{
INTÉRPRETE SURDO DE LÍNGUA DE SINAIS BRASILEIRA: O NOVO CAMPO DE TRADUÇÃO / INTERPRETAÇÃO CULTURAL E SEU DESAFIO
}

\author{
Ana Regina Campello* \\ Universidade Federal do Rio de Janeiro
}

\begin{abstract}
Resumo: Esse artigo é o resultado da pesquisa que trata da nova modalidade de tradução/interpretação de línguas de sinais dos intérpretes Surdos, observando a norma surda (STONE, 2009 apud SOUZA, 2010). Recentemente surgiu esse novo campo de tradução no contexto educacional do ensino a distância: o da tradução e interpretação do ator/tradutor e finalmente e intérprete de uma língua de sinais para outra língua de sinais (SEGALA, 2010; SOUZA, 2010). Estas atividades de tradução e interpretação têm sido desempenhadas por Surdos bilíngues intermodais. Exatamente por representar um novo campo de estudo, este artigo apresenta a sua constituição.
\end{abstract}

Palavras-chave: Intérprete surdo. Libras. Tradução. Interpretação.

\section{DEAF INTERPRETER OF BRAZILIAN SIGNS LANGUAGE: THE NEW FIELD TRANSLATION / INTERPRETATION AND ITS CULTURAL CHALLENGE}

\begin{abstract}
This article is the result of research that deals with the new mode of translation / interpretation of sign language interpreters Deaf, ob-
\end{abstract}

\footnotetext{
* Possui doutorado em Educação pela Universidade Federal de Santa Catarina (2008). Atualmente professora Colaboradora na Universidade Federal de Santa Catarina (UFSC), na Pós-graduação em Estudos da Tradução- PGET, e na Universidade Federal Fluminense (UFF). Professora Adjunto da Universidade Federal do Rio de Janeiro (UFRJ). Rio de Janeiro, Brasil. E-mail: anaregina@ letras.ufrj.br
} 
serving the deaf norm (STONE, 2009 apud SOUZA, 2010). The translation and interpretation of the actor / translator and interpreter and finally a sign language sign language to another (SEGALA, 2010; SOUZA, 2010). Recently, this new field of translation emerged in the educational context of distance education. These activities Translation and interpretation have been performed by bilingual Deaf intermodal. Exactly as it represents a new field of study, this article presents its constitution.

Keywords: Deaf interpreter. Libras. Translation. Interpretation

\section{Introdução ${ }^{1}$}

As traduções realizadas por Surdos no Curso de Letras Libras EAD e as interpretações realizadas por Surdos de uma língua de sinais internacional (ASL ou LSI) apresentam características específicas que diferenciam das traduções e interpretações realizadas pelos intérpretes de Libras. Isso começou a ser identificado na Inglaterra em contextos similares de tradução ou interpretação de língua de sinais (STONE, 2009 apud SOUZA, 2010). No Brasil, os intérpretes Surdos iniciaram estas atividades diante das necessidades que foram surgindo. No entanto, não há muitas produções nestes campos de tradução e interpretação de línguas de sinais. Os trabalhos de Segala (2010) e Souza (2010) são os primeiros a analisar as formas de tradução que se apresentam no contexto específico do Curso de Letras Libras EAD, da UFSC, em que tradutores surdos atuam sistematicamente na tradução de todos os textos em que a língua fonte é a Língua Portuguesa e a língua alvo é a Língua Brasileira de Sinais (Libras). Percebe-se que há muitas coisas interessantes a serem analisadas e que podem contribuir efetivamente para a formação de tradutores e intérpretes de língua de sinais, tanto Surdos, quanto ouvintes. O presente artigo situa-se neste contexto e apresenta a perspectiva de iniciar uma trajetória nestes campos de atuação. Também se justifica a realização deste artigo, uma vez que a língua de sinais passou a ser reconhecida como língua nacional por meio da Lei 10.436 de 2002 regulamentada pelo De- 
creto 5.626 de 2005 . Neste decreto, ainda, consta explicitamente a função da tradução e interpretação de língua brasileira de sinais e a formação de profissionais nestas áreas. A Universidade Federal de Santa Catarina - UFSC conta com os cursos de formação destes profissionais e passa a produzir pesquisas que fomentam esta formação. O exemplo é apresentado a seguir durante o desenvolvimento deste artigo. Os objetivos gerais do artigo são os seguintes:

a. identificar os registros existentes sobre a atuação de Intérpretes Surdos no Brasil;

b. analisar o desempenho/performance e identificar os elementos linguísticos, culturais e sociais que caracterizam a norma Surda nas traduções e interpretações realizadas por Surdos.

Nos itens seguintes, apresento questões pertinentes a serem discutidas e consideradas para o desenvolvimento do presente artigo. É considerada importante situar a experiência do "repetidor" dos Surdos, uma função que encontramos registros a respeito no tempo Imperial Instituto de Surdos-Mudos. Também é destacada a experiência e atuação dos Intérpretes Surdos nos cursos, palestras e eventos internacionais. Estas experiências apresentam a partir do meu lugar, enquanto Surda, por meio das minhas narrativas das pessoas Surdas, e experiências vividas dos Surdos Intérpretes dentro da comunidade surda. Apresento o perfil, o desempenho/performance e a identificação linguística (tradução cultural) que influenciaram e escolha dos sinais no ato de tradução e interpretação.

$\mathrm{Na}$ "Identificação Linguística" apresenta o que justifica a realização deste artigo, visto que até o presente momento não há registros desta tradução cultural. Através das narrativas dos Intérpretes Surdos e interlocutores, instrumento metodológico, de coleta de dados, problematizar-se-á a origem de tradução cultural e seu desenvolvimento a partir de identificação linguística.

Na "Forma de Tradução / Interpretação" se apresenta uma análise da forma de tradução / interpretação; o uso das línguas em 
eventos, tradução cultural e serviço de tradução e interpretação, e o estudo e revisão teórica de alguns autores, tais como Jakobson (1992), Schogt (1992), Quadros (2004), Stone (2009 apud SOUZA, 2010), Avelar (2009) e Souza (2010).

Nos "Aspectos a serem considerados" apresenta as propostas de análises da tradução cultural e seus performances como tradutor/ intérprete da Língua de Sinais Brasileira para a Língua de Sinais Americana e Língua de Sinais Internacionais, capítulo que representar o "reconhecimento" do trabalho dos Intérpretes Surdos.

\section{O surgimento de Intérprete Surdo de Língua de Sinais}

O papel de Intérprete Surdo de Língua de Sinais Brasileira e seu exercício já vêm desde 1875, quando Flausino Gama era "repetidor" (FELIPE, 2000) na sala de aula do Imperial Instituto de Surdos Mudos. Durante o trajeto do papel de Intérprete Surdo tem o seu destino obscuro já que a produção sobre esta função está localizada nos arquivos raros da Biblioteca do Instituto Nacional de Educação de Surdos - INES, no Rio de Janeiro. Fora do contexto educacional, muitos Surdos já exerceram suas funções fora das situações educacionais, tais como: tradução / interpretação aos Surdos no Serviço Social / Psicologia, em CABERJ do BANERJ. No entanto, somente em 1993 há o reconhecimento do uso do Intérprete Surdo da modalidade interlingual (no sentido de JAKOBSON, 1992)1 no espaço acadêmico. Isso acontece na Universidade Federal do Rio de Janeiro-UFRJ, quando foram promovidos os cursos no pré - II Congresso Latino Americano de Bilingüismo (Língua de Sinais / Língua Oral) para Surdos. Os cursos elaborados pelos professores Surdos: americano Ken Mikos e sueco Mats Jonsson foram traduzidos / interpretados pelo intérprete Surdo de ASL/Libras, Nelson Pimenta de Castro.

Também tivemos este tipo de atuação em 2010, por ocasião do V Congresso Deaf Academics, realizado na UFSC. Nesta ocasião, tivemos vários intérpretes Surdos fazendo a interpretação simul- 
tânea da ASL para a Libras, assim como também da LSI para a Libras. A LSI é um sistema de sinais internacionais com o objetivo de melhor entendimento o uso de várias línguas de sinais, para criar uma língua fácil de aprender e de se comunicar. É uma língua que surgiu a partir dos encontros das lideranças surdas européias e passou a ser usada sistematicamente em eventos internacionais.

Com o surgimento do Curso de Letras Libras, a atividade de tradutor / ator de língua de sinais (QUADROS, 2008; AVELAR, 2009; SOUZA, 2010) propulsionou a carreira de tradução no AVEA, produzindo Normas Surdas de Tradução - Deaf Translation Norm (STONE, 2009 apud SOUZA, 2010) em nível acadêmico, desempenhadas quase que exclusivamente por pelos tradutores/atores Surdos bilíngues para o Ambiente Virtual de Ensino e Aprendizagem - AVEA e para os DVDs. Além disso, no desenvolvimento de algumas disciplinas, também houve a tradução / interpretação nestas modalidades, por exemplo, a atuação pioneira de uma intérprete Surda na disciplina de Análise do Discurso, de Letras Libras, turma 2006. A adequação de normas, função e de novo campo de trabalho foi tomando corpo e passou a ser reconhecida, culminando na inclusão de candidatos Surdos para a realização do Exame Prolibras na qualidade de tradutores/intérpretes de línguas de sinais, a partir de 2009.

\section{Identificação Linguística}

A definição da comunidade Surda que reforça o sentido histórico, linguístico e cultural constituído de pessoas Surdas onde são inseridas em várias áreas, pois os Surdos ocupam em vários espaços. Neste contexto objetiva-se também que todos conheçam para que possam integrar-se a essa comunidade, com isso deixarão de serem minorias e será um todo. A comunidade está dividida em vários setores, mas os espaços que mais ocupam são os três principais: familiar, escolar e social, por isso reflete-se sobre a importância da língua de sinais para a comunidade surda. As pessoas ouvintes 
usam a audição como funcionamento auditivo pela habilidade nos atos do ouvir e do falar. Acontece o mesmo com as pessoas Surdas que usam as mãos como funcionamento visual pela habilidade nos atos do ver e do sinalizar.

Os Surdos usam a língua de sinais brasileira envolvendo o corpo todo, no ato da comunicação. Sua comunicação é do viso-gestual e produz inúmeras formas de apreensão, interpretação e narração do mundo a partir de uma cultura visual. A cultura visual vem da "experiência visual” (PERLIN, 1998) que é um "espaço de produção" (QUADROS, 2007) da constituição dos Surdos que apresenta seus diversos artefatos, como: língua de sinais, história cultural, identidade, pedagogia, literatura, artes, trabalho, tecnologia, teatro, pintura, e outros. Complementando com o Quadros (2007) de que "o artefato cultural tem validação enquanto sustenta o pertencimento cultural" 2 .

Para captar as mensagens e sua tradução / interpretação exige uma profunda reflexão, como escreve Luklin (2005, p. 44):

Escutar uma comunidade que usa um código lingüístico distinto do nosso, buscando uma imersão nos aspectos culturais que cercam o diálogo, o monólogo, as narrativas em grupo, as arquiteturas da justiça e do rumor, as expressões peculiares, a gíria, a definição de gêneros, não é tarefa que possa ser cumprida pelo sentido exclusivo do ouvir. O olhar passa a ser fundamental. Ela colabora para o descentramento do sujeito moderno obrigando o uso do corpo de forma diferente dos nossos códigos cotidianos. Implica uma mobilidade dos olhos, da cabeça, do rosto, das mãos, dos braços, organizados de forma diferente. Solicita uma agilidade de percepção, uma plasticidade do cérebro.

Ao interpretar / traduzir, o tradutor e o intérprete Surdo transportam a experiência visual aquilo o que foi vivenciado ou conhecido por meio da língua de sinais, selecionando o "final" da história 
para dar ao "ponto de partida" no começo da fragmentação desta história, através de tradução cultural que tratarei a seguir.

A tradução cultural, segundo Walter Benjamin3 (1980, p. 9-21) define como um reenquadramento conceitual da tradução na sua relação com língua, texto e cultura, assumida como metáfora que designa o problema central da condição pós-colonial. Isso quer dizer que a cultura passa a ser um elemento de "identificação linguística" (MARTINS, 2004) como um lugar ou um espaço que não é constante de passagem entre as duas línguas: falada e sinalizada, de passagem de identidades Surdas, de desestabilização das referências culturais orais e visuais, um espaço de intervalo de tempo antes do qual determinado ato não pode efetuar-se na negociação de sinais, não uma totalidade fechada.

Sobre Cultura, a palavra vem do latim que significa "cultivo agrícola", e para a comunidade Surda, o sentido pode ser traduzido o cultivo da linguagem, da identidade e da língua de sinais. Há muitas discussões para o conceito de cultura, e escolhemos uma definição definido por Strobel (2008) e do Echeverria (1998), que dizem:

[...] da mesma forma, um ser humano, em contato com o seu espaço cultural, reage, cresce e desenvolve sua identidade, isto significa que os cultivos que fazemos são coletivos e não isolados. A cultura não vem pronta, daí porque ela sempre se modifica e se atualiza, expressando claramente que não surge com o homem sozinho e sim das produções coletivas que decorrem do desenvolvimento cultural experimentado por suas gerações passadas (STROBEL, 2008, p.19).

[...] mediada ou indireta que cultiva a dimensão formal e dramática das ocupações próprias da vida cotidiana $(\mathrm{ECH}-$ EVERRIA, 1998, p.132). 
A cultura é uma construção de identidade e de língua comunitária, de reprodução de gerações passadas através da dimensão meta-visual da existência, que passa pelo natural, mas o transforma, sendo uma entranhável. Essa construção é política e de identitária, num sentido amplo de polis, de grupos mais ou menos coesos de seres humanos, que criam iconicidade e de sinalários próprios e convencionados e que serão percebidos como parte arragaida durante a sua existência.

Como fazer uma tradução cultural com os sinais e sua expressão? Quanto de uma cultura da fonte pode ser traduzido através de sinais que originaram em outra cultura diferente do alvo? Em que sentido a teoria da tradução pode ser aplicada e performances culturais que incluem, além das expressões que são produto de outros níveis de linguagem? Por que os interlocutores Surdos se interessam mais com as expressões e informações dos Intérpretes Surdos? Como em "A tarefa do tradutor", de Benjamin (1980), o que é essencial de uma cultura não é o enunciado que se comunica, mas aquilo que excede a comunicação. Na tradução cultural na abordagem da Masutti (2008) consiste a cultura como significantes abertos, isto é, as percepções de corpo, movimento e olhar como fundamentos constituivos do tradutor / intérprete de língua de sinais. A outra abordagem desenvolvida pelo Segala (2010) que descreve o papel do tradutor intermodal e intersemiótico pelas raízes culturais e uma boa experiência na vida social em ambas as línguas, e que deve conhecer profundamente as várias nuances das duas culturas, encarando não só a estrutura linguística, mas também a vida cultural de uma sociedade. Para complementar, Quadros e Souza (2008, p.1) explicitam que:

Somado a isso, pretendemos considerar também a relevância da tradução para se construir espaços híbridos interculturais, pois, no caso desse curso, a Língua Brasileira de Sinais é a língua de instrução, embora ainda os textos-fonte estejam na versão escrita da Língua Portuguesa. 
Segundo Walter Benjamin (1980, p. 9-21), a tarefa do tradutor cultural ao tentar fazer com que uma cultura não somente se busca a tradução da língua, mas amplia-se o leque e busca-se traduzir a cultura do interlocutor nas suas distintas níveis de habilidades. O que importa é a busca do outro espaço, ou seja, tentar intermediar o entre-lugar, o espaço entre as duas culturas em questão para que estas informações possam chegar ao público alvo.

Para isso, na tradução cultural entre fonte-alvo há uma ligação evidente no uso da semântica e a tradução. O autor Schogt (1992) explica que há transferência do significado da fonte e a outra do significado do alvo. Mas as teorias da semântica e da tradução ainda estão em estudo sobre significado, seu nível e da comunicação entre indivíduos que falam a mesma língua. Portanto este artigo, em futuro próximo, vai contribuir mais a área de tradução.

$\mathrm{O}$ interesse do interlocutor pelo Intérprete Surdo e seu desempenho / performance só acontecem quando o Intérprete recebe uma mensagem e a interpreta. Se seguir as regras gramaticais, utilizar as expressões faciais/corporais e tiverem o mesmo sinalário, a mensagem chega sem grandes mudanças, mas, caso houver mudanças de elementos estranháveis (dependendo do contexto cultural) a tradução / interpretação podem ser inseridas em outros aspectos da gramática da língua de sinais, como descrição imagética, exemplificação, com a finalidade de esclarecer o conteúdo da tradução.

A metodologia será baseada nas estratégias metodológicas por Williams e Chesterman (2002 apud SOUZA, 2010) que na investigação "procura por novos dados, novas informações derivadas da observação de dados e do trabalho experimental; e ainda, procura evidências que dêem suporte ou não confirmem hipóteses, ou gerem outras". Por isso, esta metodologia é aplicada neste artigo como caso observacional, descritivo e analítico em tradução, com o objetivo de descrever o nosso caso: desempenho da tradução / interpretação cultural do tradutor / intérprete Surdo. Isso consiste em avaliar os dois intérpretes / tradutores Surdos na sala de aula através do vídeo conferência no ato da tradução / interpretação de língua de sinais brasileira para língua de sinais americana e vice 
versa. As ferramentas serão utilizadas através de gravação de vídeo por câmeras digitais, sala de aula (ou estúdio onde será realizada a vídeo conferência) e presença dos professores-mediadores.

\section{Forma de Tradução / Interpretação}

O que motiva os Intérpretes Surdos a sua forma de tradução e de interpretação?

As narrativas pessoais serão recolhidas dos intérpretes surdos que, normalmente, falam sobre o quanto os tradutores surdos são hábeis na comunicação da informação para surdos. Alem disso, eles mencionam de forma recorrente o contraste entre os tradutores e intérpretes surdos e os tradutores e intérpretes ouvintes. Entre os aspectos comumente ressaltados, listo os seguintes:

a. o conflito de entender a tradução "aportuguesada";

b. não possuir os aspectos culturais da comunidade Surda.

c. Os intérpretes não-surdos não tem base da língua de sinais americana, nem da língua de sinais internacionais e dificuldade de fazer tradução cultural da comunidade Surda;

d. Não tem base completa da língua de sinais da comunidade Surda;

e. Dificuldade de entender a soletração rítmica;

f. Os intérpretes não-surdos têm dificuldade de usar as descrições imagéticas.

Este artigo, portanto, coletou as narrativas desses tradutores surdos para verificar as razões que os levam a falar sobre isso dessa forma. O objetivo é identificar as representações e as razões que as justificam a partir dos próprios tradutores.

A tradução / interpretação exige formação, pois envolve vários fatores, entre os quais, o fato de estarmos diante de línguas de diferentes modalidades, as culturas que se traduzem nestas línguas; 
as formas de apresentar os conceitos em cada uma destas línguas. Dessa forma, deve-se levar em consideração também a performance do Intérprete Surdo, conforme o depoimento da Sueli Ramalho (abril, 2011) quando assistiu na conferência pela primeira vez a presença da tradutora / intérprete na disciplina de Sintaxe do EAD - Letras-Libras na UFSC:

A atuação da Profa. Ana Regina sendo surda, tranquilamente passou a ter seu papel de mediadora na comunicação com as pessoas surdas, demonstrando a capacidade, qualidade e a habilidade natural com conhecimento da estrutura gramatical da língua de sinais, sem perder valores culturais e costumes da comunidade surda

No caso da capacidade e transmissão do conteúdo, Sueli Ramalho comenta novamente:

A mesma capacidade da atuação, transmissão do conteúdo, entendimento mútuo, é homogêneo por tratar da mesma língua materna, não pode ser comparada com uma pessoa não nativa da língua como todo existe exceções, mas não há dúvida que a maioria pessoas não surdas que considera conhecedor desta língua não conseguem ser bom mediador quando estão tentando transmitir para o surdo do que está sendo dito, ao contrário do surdo mediador que tem se esforçado em quebrar a barreira e alcançado o aprendizado de duas línguas.

Sueli Ramalho, uma tradutora surda, acredita a capacidade laboral das pessoas Surdas em serem Intérpretes / Tradutores de Língua de Sinais Brasileira, como vemos os comentários:

Atualmente já contamos com várias pessoas surdas que tem essa capacidade de transmitir, e a Profa. Ana Regina aos 
poucos tem quebrado do paradigma que a sociedade majoritária tem colocado limitações aos surdos que não teriam condições de poder estar neste patamar.

A mesma tradutora reafirma a sua eficácia do uso da língua:

Não há dúvida que o aprendizado do surdo acerca a segunda língua e posteriormente ser o mediador é muito mais eficaz do que pessoa não surda aprender a segunda língua e tentar ser o melhor mediador.

Jakobson (1992) afirma que a tradução tem três diferentes maneiras de interpretar o signo visual. Ele pode ser traduzido em outros signos da mesma língua, em outra língua, ou em outro sistema de símbolos não visual. Esses três tipos de tradução podem ser:

a. tradução intralingual, que é uma interpretação de signos verbais por meio de outros signos da mesma língua. De um signo, dentro de uma mesma língua, usa tanto outro signo como outros recursos mais ou menos sinônimos, homônimos, polissemia, descrição imagética para uma circunlocução. Um signo ou expressão idiomática só pode ser completamente interpretado por meio de uma combinação equivalente de unidades de códigos, no caso da função dos atores/tradutores do AVEA e dos DVDs da Letras Libras;

b. tradução interlingual, que é a interpretação de signos visuais por meio de alguma outra língua - não há equivalência completa entre códigos, as mensagens podem servir como interpretações adequadas de códigos ou mensagens estrangeiras. O mais frequente é a tradução de uma língua, dentro de outra, substitui mensagens em uma língua, não por unida- 
des de códigos separados, mas por mensagens inteiras em algumas outras línguas. Tal tradução é um discurso direto, ou seja, o tradutor recodifica e transmite a mensagem recebida de outra fonte. Então, a tradução envolve duas mensagens equivalentes em dois códigos diferentes, em duas línguas diferentes, como é o caso da língua de sinais brasileira para língua de sinais americana e vice versa. O depoimento José Arnor (Rio Grande do Norte) complementa a sua justificativa da tradução interlingual:

Achei que legal, sim o que mais importante é visualização mas é complicado pq quando ela falar de ASL agente entender mas não conseguir contexto mas por exemplo sinal ja conheço mas so sinal sim o resto não por isso precisar interpretação ASL outra coisa quando palestrante na hora sinalização mas não consegui por que complicado na hora bimodal na hora eu vejo complicado precisar fechar a boca. eu conseguir entender ok? Ana Regina interpretou será importante juntos sim pq ASL não conheço bem qualquer momento precisar sim não é por causa gestual nada ver com isso precisar esta aqui presença interprete pelo surdos sim não precisar ouvinte pq já formação asl se surdos entendi coisa ASL. Ela explico detalhe tudo mas Tradução foi ótimo Ana Regina entendi tudo mas eu vejo comparação Melanie diferente sinalização alguns conheço sinal mas não conseguir contexto ok?

c. tradução intersemiótica, que é uma interpretação de signos visuais por meio de um sistema de signos não visuais.

E a tradução cultural traduzido e interpretado pelos Intérpretes Surdos? Por isso, a tradução cultural é considerada pelo presente artigo como fundamental, pois capta a língua de sinais, e a língua portuguesa como línguas imersas na cultura, destacando principal- 
mente do uso da tradução e que a mesma ocorre na maioria das vezes, voluntariamente, porque não se decide naquele exato momento que se vai traduzir determinado sinal ou expressão, mas ela ocorre sem que percebamos, mesmo que mentalmente, o que não deixa de ser uma forma de tradução.

Então, é de suma importância que novos estudos continuem sendo feitos com relação ao que vem a ser o uso da tradução nas aulas de língua estrangeira realmente, e o que pode ser definido como tradução para que o ensino/aprendizagem de línguas seja melhorado.

Destaco a importância da análise a diferença cultural de dois tradutores de língua de sinais como resultado preliminar inicial da análise. A metodologia adotada é de comparação entre as performances e de tradução de dois tradutores de língua de sinais brasileira (Libras) e de língua de sinais americana (ASL) da música "Imagine" de John Lennon, como obervam as figuras 1 e 2 abaixo:

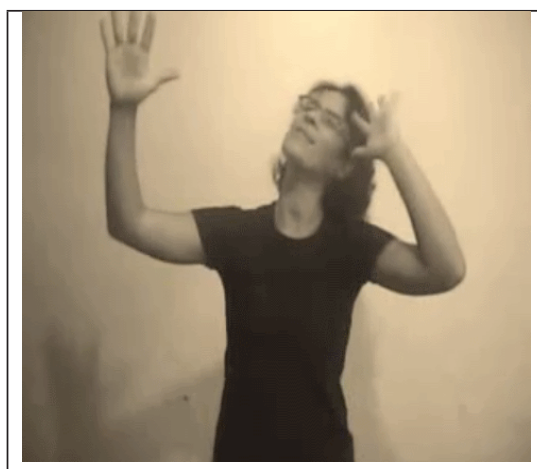

Figura 1: http://www.youtube.com/watch Figura 2: http://www.youtube.com/wa ? $\mathrm{v}=\mathrm{ZD}$ sjIA8-r44


$\mathrm{tch} ? \mathrm{v}=4 \mathrm{fBh} 2 \mathrm{Tcb} 1 \mathrm{E} 4 \&$ feature $=$ related

Logo, ao observarmos tais performances e, com base da metodologia da língua alvo, e analisados as seguintes aplicações e adaptações nos procedimentos tradutórios (GILES, 1995 [2009]) de modo geral, que são: 
a. a informação na língua alvo contém a mensagem (M) apresentada na língua fonte;

b. a língua alvo apresenta os três tipos de informação analisados: informação contextualizadora $(\mathrm{FI})$, informação induzida ou motivada por questões linguísticas (LII) e a informação pessoal (PI).

Especificando o procedimento tradutório do Giles (1995 [2009]):

1. Mensagem - na língua fonte pode gerar sentenças diferentes na língua alvo, que podem ser consideradas, com legitimidade, traduções.

2. Informação contextualizadora (FI) - a informação está atrelada ao acréscimo de informação para ajustar, compor, enquadrar e emoldurar o significado da mensagem, como o propósito de contextualizar o significado sugerido no texto da partida para o leitor de chegada.

3. Informação induzida ou motivada por questões linguísticas (LII) - refere ao tipo de informação adicionada por questões de adaptação ao sistema linguístico de chegada. Isso, quer dizer, que os ajustes são demandados pelo sistema linguístico e não por decisão profissional ou intérprete por questão de convenções e regras de uso prático na língua de chegada.

4. Informação pessoal (PI) - informações adicionadas à mensagem e diretamente associadas ao estilo do tradutor / intérprete, ou a outras idiossincrasias que revelam sua personalidade, seu contexto sócio-cultural ou em relação do grau do conhecimento do leitor de texto.

$\mathrm{Na}$ análise preliminar, podemos observar os quatro quadros com os quatros procedimentos tradutórios diferentes abaixo: 


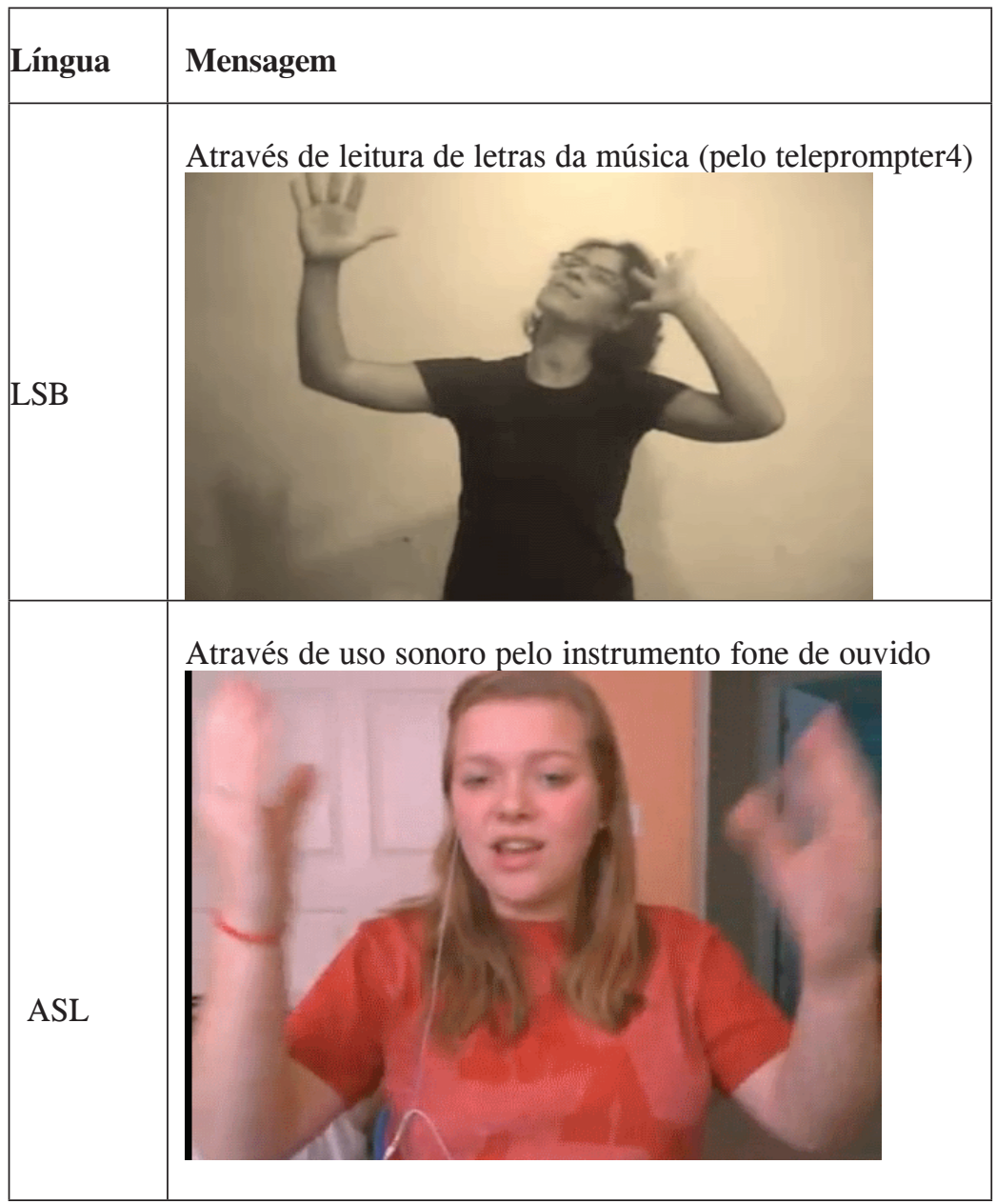

Quadro 1 







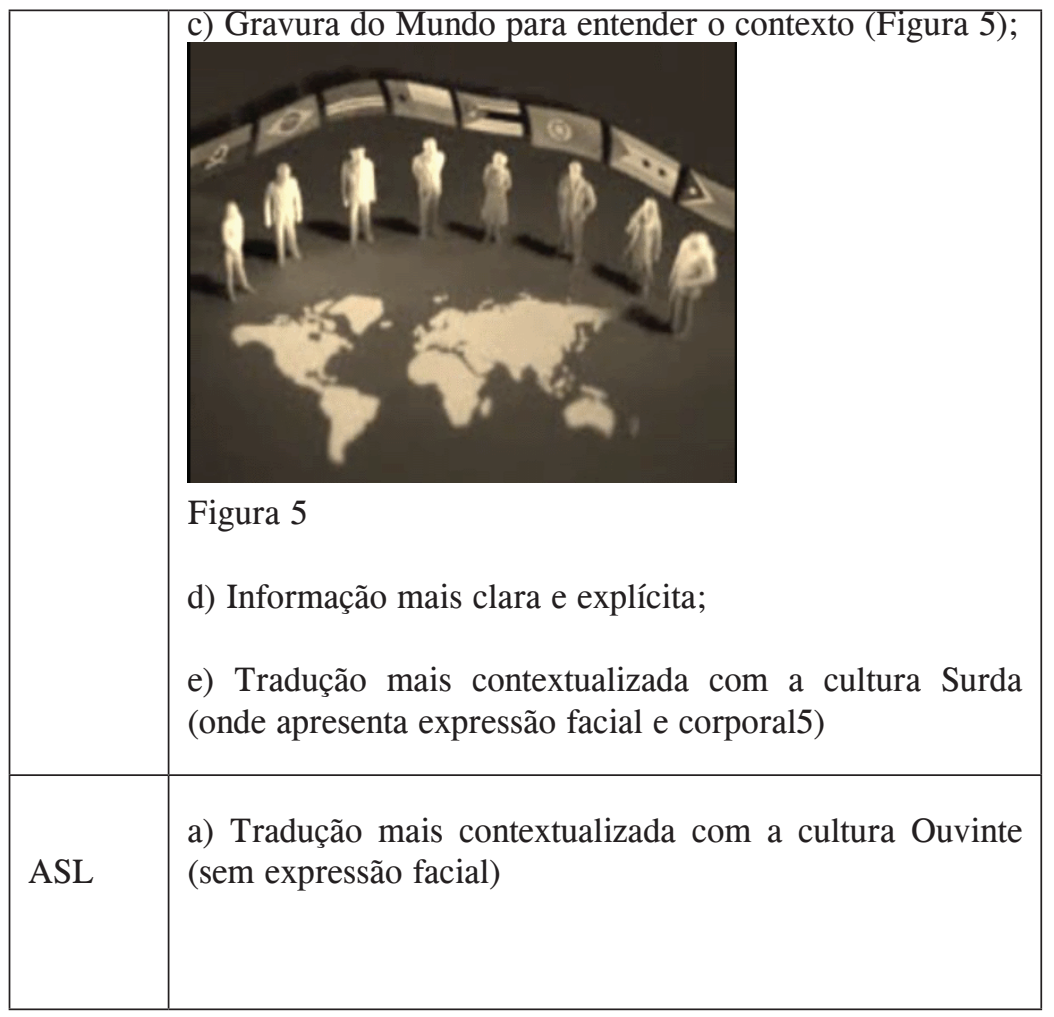

Quadro 2

\begin{tabular}{|l|l|}
\hline Língua & \multicolumn{1}{|c|}{ Informação Induzida ou por questões linguísticas - LII } \\
\hline LSB & $\begin{array}{l}\text { a) Regras e convenções da LSB da comunidade Surda } \\
\text { brasileira; } \\
\text { b) Sinais específicos da LSB de acordo com a música; } \\
\text { c) Uso de classificadores (árvores, montanhas, etc) }\end{array}$ \\
\hline
\end{tabular}




\begin{tabular}{|l|l|}
\hline & $\begin{array}{l}\text { a) Regras e convenções do SEE (Signing Exaclt English - } \\
\text { Inglês sinalizados junto com a oralização); }\end{array}$ \\
ASL & $\begin{array}{l}\text { b) O sinal "futuro" aparece no início da sinalização; } \\
\text { c) Inclusão do sinal "vida" o que não constava no texto }\end{array}$ \\
\hline
\end{tabular}

Quadro 3

\begin{tabular}{|l|l|}
\hline Língua & Informação pessoal (PI) \\
\hline LSB & Nenhuma \\
\hline ASL & Nome da tradutora no começo do filme em datilologia \\
\hline
\end{tabular}

Quadro 4

Concluindo que os dois tradutores utilizam a mensagem (M) bem preservada, sendo que a tradutora da LSB usou as informações contextualizadas (FI) bem claras para expressar melhor o sinalário (léxico). Evidencia a tradução de acordo com a cultura Surda.

A tradutora de ASL não preservou e não utilizou a informação induzida (LII) ou motivada por questão linguística para chegar às informações ao público alvo, por utilizar o léxico em mesmo sinalário de modo preservado e convencional. Não evidencia a tradução da cultura Surda mesmo usando a língua da comunidade surda norte-americana (SEE6) que mostra a distinção da ASL da comunidade Surda. Para comprovar a teoria de que a tradutora na tradução de ASL não condiz à cultura surda (STROBEL, 2008) e (BAHAN, 2011) como demonstra a crítica de um usuário no youtube: 
Great video! Your signing is really fluid. My only suggestion would be to be careful that you don't switch from ASL to PSE or SEE. Some of your signed sentences seem to be an exact translation of the English words, which does not work in ASL. Nice job otherwise, though!

Outra crítica fundamental: "this version is also different because there is not set way to sign a song. You interprete the lyrics not translate it."

Isso demonstra que a cultura Surda e sua música exige mais performance para atingir de fato a cultura Surda que, segundo Bahan (2011) "Before talking about deaf culture and what is culture, let us talk about sensory worlds.!Sensory worlds help us make sense of Deaf Culture."7

Este presente artigo fundamenta a inclusão das informações que apresentam alterações, dentre outros fatores, por conta de efeitos de modalidade das línguas em contato nas traduções ou outros fatores, tais como, o fato de estarmos trabalhando com a interpretação simultânea que envolve limitações relacionadas com o tempo de processamento da informação.

Esclareço que o presente artigo caracteriza-se com um estudo de caso observacional, descritivo e exploratório da tradução de dois tradutores, que apresenta como reflexão sobre os resultados da tradução entre as duas línguas de sinais. Este artigo é um dos primeiros trabalhos realizados neste campo específico de tradução no Brasil.

\section{Aspectos a serem considerados}

Mais uma vez, é possível ver esse momento com muito otimismo e expectativa. E pensar que a Libras já é legalizada, e que já são instituídos os direitos dos surdos (apesar de estar tudo no começo) e agora também legalizada a profissão do intérprete, temos uma 
nova geração abraçando e acreditando nesse legado. Como diz no sites do Marildo José Nercolini em 18 de julho de 2005:

\begin{abstract}
A tradução cultural coloca uma questão fundamental para os dias de hoje: como entender/compreender uma cultura que não seja a minha? Como conviver com esse Outro, tendo presente o que nos aproxima e o que nos afasta os conflitos e o diálogo. Não é uma interpretação para minha cultura do que seja o Outro, muito menos sua versão aceitável/palatável. A tradução cultural implica um contato cultural profundo entre duas ou mais culturas. Aproximar-se e deixarse tocar pelo desconhecido, mesmo correndo-se o risco do enfrentamento, do conflito, parece ser uma maneira mais profícua e certamente mais trabalhosa de tradução cultural.
\end{abstract}

Possibilidade-impossibilidade: a tradução trabalha nesse limiar: entre a impossibilidade da tradução total e completa e as muitas possibilidades de diálogos, aproximações, tentativas melhores sucedidas, embates...

Neste tipo de situação, a formação de um intérprete / tradutor de língua de sinais profissional, acadêmico e reconhecido é necessária na área de tradução. O meu trabalho como pesquisadora é analisar aspectos e específicos que possam contribuir para algo, por exemplo, a formação de tradutores e intérpretes Surdos de língua de sinais. 


\section{Notas}

1. Jakobson (1992) afirma a tradução interlingual, que é a interpretação de signos verbais por meio de alguma outra língua.

2. Quadros, Ronice \& Perlin, Gladis. O debate sobre o surdo e a inclusão. Versão preliminar do material de formação docente - SESI. p.16, 2007.

3. Todas as citações de Walter Benjamin de "A tarefa do tradutor" são do texto traduzido por Maria Filomena Molder.

4. Teleprompter - As pessoas que trabalham ou lêem em frente das câmeras de TV e utilizam diferentes tipos de teleprompters para auxiliar a leitura de seus textos.

5. Um dos componentes fonético mais importante da gramática da língua de sinais brasileiro, assim como outras línguas sinalizadas.

6. Mistura de duas línguas (inglês e ASL) considerada como indesejável. A maioria perde muito nas competênciasde comunicativas dentro da comunidade Surda.

7. Tradução: "Antes de falar sobre a cultura surda e o que é cultura, vamos falar sobre o mundo sensorial! Mundo sensorial nos ajudar a fazer o conceitoda Cultura Surda".

8. http://www.literal.com.br/acervodoportal/a-questao-da-traducao-cultural-1089/ 


\section{Referências}

AVELAR, Thaís Fleury. A Questão da padronização linguística de sinais nos atores-tradutores surdos do Curso de Letras-Libras da UFSC. 2009. Dissertação (Mestrado)- Universidade Federal de Santa Catarina, Centro Comunicação e Expressão, Programa de Pós-graduação em Estudos da Tradução. Florianópolis, 2009.

BAHAN, Benjamin. Sentidos e Cultura: Explorando Orientações Sensoriais. In: MOURA, Cecília ata lii. Educação para Surdos: Práticas e Perspectivas II. São Paulo: Santos Editora, 2011. p. 95-121.

BENJAMIN, Walter. A Tarefa do Tradutor (Die Aufgabe des Übersetzers, Gesammelte Schriften). Tradução Maria Filomena Molder. IV.1. 1980. p. 9 -21. Disponível em: <http://www.c-e-m.org/wp-content/uploads/a-tarefa-do-tradutor.pdf $>$.

CAMPELLO, Ana Regina. Intérprete surdo de língua de sinais brasileira: o novo campo de tradução / interpretação cultural e seu desafio. Projeto de Pesquisa de Pós-graduação. Universidade Federal de Santa Catarina, Centro Comunicação e Expressão, Programa de Pós-graduação em Estudos da Tradução. Florianópolis, 2011.

ECHEVERRÍA, Bolívar. La Modernidad de lo Barroco. México (D.F.): ERA, 1998.

FELIPE, T. A. De Flausino ao Grupo de Pesquisa da FENEIS - RJ. In: Seminário Nacional do INES, 5, 2000, Rio de janeiro. Anais... Rio de Janeiro: INES, 2000. p. $87-89$.

GILE, D. Fidelity in interpretation and translation. In: . Basic concepts and models for interpreter and translator training. v.8. Amsterdam: John Benjamins, 1995 [2009]. p. 49-74.

JAKOBSON, Roman. On Linguistic Aspects of Tranlation. In: Shulte, Rainer; Biguenet, John. (Ed.). Theories of Translation: an anthology of essays from Dryden to Derrida. Chicago \& London: The University of Chicago Press, 1992. p.144-151. 
LULKIN, Sérgio Andres. O discurso moderno na educação dos Surdos: práticas de controle do corpo e a expressão cultural amordaçada. In: Skliar, Carlos (Org.). A Surdez: um olhar sobre as diferenças. 3 ed. Porto Alegre: Editora Mediação, 2005.

MARTINS, André Luís Batista. Identidades Surdas no Processo de Identificação Linguística: o entremeio de duas línguas. Dissertação (Mestrado). Universidade Federal de Uberlândia. Uberlândia (MG), 2004.

MASUTTI, Mara. A formação de tradutores/Intérpretes de Língua de Sinais em perspectiva. In: X Encontro Nacional de Tradutores e IV Encontro Internacional de Tradutores, 10, 2008, Ouro Preto. Resumos... Ouro Preto: ABRAPT, 2008.

PERLIN, G. Identidades surdas. In: Skliar, Carlos (Org.). A Surdez: um olhar sobre as diferenças. Porto Alegre: Editora Mediação, 1998.

QUADROS, Ronice Muller. O tradutor intérprete de língua brasileira de sinais e língua portuguesa. MEC - SEESP. Brasília, 2004.

QUADROS, Ronice ; SOUZA, Saulo. Aspectos da Tradução/Encenação na Língua de Sinais Brasileira para um Ambiente virtual de Ensino: Práticas Tradutórias do Curso Letras Libras. In: QUADROS, Ronice (Org.). Estudos Surdos III. Petrópolis: Editora Arara Azul, 2008.

QUADROS, Ronice; PERLIN, Gladis. $O$ debate sobre o surdo e a inclusão. Versão preliminar do material de formação docente - SESI. 2007. p. 16.

SCHOGT, Henry. Semantic Theory and Translation Theory. In: Shulte, Rainer; Biguenet, John. (Ed.). Theories of Translation: an anthology of essays from Dryden to Derrida. Chicago \& London : The University of Chicago Press, 1992. p. 193-203.

SEGALA, Rimar. Tradução Intermodal e Intersemiótica/Interlingual: Português brasileiro escrito para a Língua Brasileira de Sinais. Dissertação (Mestrado)-

Universidade Federal de Santa Catarina, Centro Comunicação e Expressão, Programa de Pós-graduação em Estudos da Tradução. Florianópolis, 2010. 
SOUZA, Saulo Xavier. Tradução para a Língua brasileira de Sinais: descrição de performances observadas no curso de Letras-Libras. Dissertação (Mestrado)-

Universidade Federal de Santa Catarina, Centro Comunicação e Expressão, Programa de Pós-graduação em Estudos da Tradução. Florianópolis, 2010.

STROBEL, Karin. As imagens do outro sobre a Cultura Surda. Florianópolis: EdUFSC, 2008.

Recebido em: 24/10/2013

Aceito em: 17/01/2014 
